\title{
Abordaje legislativo de la propiedad comunitaria de los Pueblos Originarios en territorio bonaerense
}

\begin{abstract}
Natalia Lorena Barriviera ${ }^{1}$
"En la concepción indígena no aparece la persona como propietaria de la tierra, sino, antes bien, la tierra como propietaria de la persona"
\end{abstract}

Arturo Bronstein (OIT)

\section{La relación de los Pueblos Originarios con la Tierra}

La relación de los pueblos indígenas con la tierra es espiritual y religiosa. Es esa relación con la madre tierra y los recursos naturales, la que permite que estos pueblos (o comunidades, centrándonos en el grupo, jamás en el individuo) logren su identidad. $^{2}$

"La relación de los Pueblos Indígenas con la tierra es espiritual y religiosa; ésta constituye un elemento integrante de la cosmovisión y con ella se mantiene una relación diagonal, circunstancia que explica el rechazo a la idea de relación de poder o de dominación entre el sujeto y la cosa que presuponen los derechos reales clásicos. De allí que, sin esa relación con la tierra los indígenas no puedan alcanzar su identidad, pues ésta es un espacio cultural penetrado de valores y tradiciones $y$ además, un ámbito comunitario, es decir, de significación

\footnotetext{
1 Abogada-Escribana (UNLP) Profesora Adjunta Ordinaria en Derecho Notarial y Registral, Secretaria Instituto de Investigación en Derecho Notarial y Registral (Fac. Cs. Jcas. y SocUNLP) correo electrónico barri_natalia@yahoo.com.ar.

2 Esta relación entre el hombre y la tierra, se aleja claramente de la concepción privatista que tenemos y que ha sido plasmada en el Código Velezano respecto a la relación de poder o señorío del hombre sobre la cosa, como una relación estrictamente patrimonial.
} 
colectiva, en el sentido que la pertenencia de ésta no se centra en el individuo, sino en el grupo y su comunidad...."3

De estas primeras apreciaciones, se desprenden los vocablos pueblo o comunidad, tierra e identidad cultural, que cobran importancia en estos momentos previos a ingresar en el análisis de la propiedad comunitaria de las tierras por parte de los pueblos originarios.

Es por ello, que creo necesario aclarar que utilizaré como sinónimos los conceptos de Pueblo Indígena y Comunidad, dejando plasmadas sus diferencias, ya que Pueblo indígena: es el conjunto de comunidades que pertenecen a un mismo antepasado común o etnia ${ }^{4}$ y Comunidad, es la unidad económica solidaria fundada en los vínculos étnico-socio-culturales y parentales.

Los términos tierra o territorio comprenden las facetas espirituales del vínculo con los Pueblos Originarios, y es lo que cubre la totalidad del hábitat de las regiones que ocupan o utilizan dichos pueblos. Es importante destacar que el alcance de los términos tierra o territorio, exceden la órbita estrictamente patrimonial, ya que permite preservar la identidad cultural y el hábitat.

La posesión de la tierra permite preservar la identidad cultural, el lenguaje, los valores, el estilo de vida y el derecho de los pueblos originarios. De allí se desprende la importancia que tiene la tierra y el derecho a ésta, para que perdure la cultura aborigen.

La sociedad argentina debe responsabilizarse de la histórica deuda que tiene con los pueblos originarios, cuya cultura

\footnotetext{
3 Vázquez, Gabriela A., "La propiedad comunitaria de los pueblos indígenas argentinos. A propósito de las XXII Jornadas Nacionales de Derecho Civil, Córdoba, 2009", JA, 25-112009, Lexis N00003/014779

4 El pueblo indígena está conformado por la suma de comunidades -aún las dispersas geográficamente-que tienen antepasados comunes.

5 Es el conjunto de personas y/o familias que habitan en un mismo lugar y tiene, a su vez, una raíz común y participan de la misma cultura.
} 
ancestral ha negado una y otra vez, transformándolos en víctimas, quitándoles territorios, arrancándoles costumbres, obligándolos a alinearse con las políticas estatales temporales e intereses económicos más fuertes, resistiendo como pudieron a todo tipo de maltratos, sometimientos, despojos y abusos, desconociéndoles sus derechos tanto humanos como colectivos.

No es en vano mencionar una frase que resuena constantemente y dice que "la Argentina aún hoy sigue negando a los bijos de la tierra". Históricamente las comunidades indígenas en nuestro país y en Latinoamérica, se encuentran reclamando el reconocimiento efectivo de sus derechos y de sus tierras.

\section{Los derechos de los Pueblos Originarios en la Constitución Nacional}

Recién en el año 1994, la Constitución Nacional reconoció la preexistencia étnica y cultural de los Pueblos Indígenas de la Argentina, admitiendo entonces que estos pueblos son anteriores al nacimiento del Estado. ${ }^{6}$

El inciso 17 del artículo 75 de la Constitución Nacional -CN- (según la Reforma de 1994), dispone "Reconocer la preexistencia étnica y cultural de los pueblos indigenas argentinos. Garantizar el respeto a su identidad y el derecho a una educación bilingüe e intercultural; reconocer la personería jurídica de sus comunidades, y la posesión y propiedad comunitarias de las tierras que tradicionalmente ocupan; $y$

\footnotetext{
$6 \quad$ A la llegada de los españoles, habitaban y poblaban el actual territorio de la República Argentina, aproximadamente veinticuatro grupos: 1) Atacamas; 2) Omaguacas o Humahuacas; 3) Diaguitas o Calchaquíes; 4) Lules-Vilelas; 5) Tonocotes o Juries; 6) Sanavirones; 7) Comechingones; 8) Huarpes; 9) Chanes; 10) Mataco-Mataguayos; 11) Mbaya Guaikuru; 12) Chiriguanos; 13) Guaraníes; 14) Caingang; 15) Chana-Timbu; 16) Charrúas; 17) Tehuelches septentrionales, 18) Tehuelches meridionales; 19) Onas; 20) Querandíes; 21) Pehuenches; 22) Yamanas; 23) Alakaluf; 24) Mapuches y en el siglo XVIII, los Ranqueles, fusión de pehuenches, mapuches y tehuelches y, los Kollas, mezcla de los omaguacas, apatamas y otros grupos locales de origen quechua y aimara. Información extraída del Capítulo VII -Propiedad Comunitaria Indígena. Verónica Kozak de Valdés- Manual de Derechos Reales-Directora Miriam Smayevsky Ed La Ley, 2015 C.A.Bs.As.
} 
regular la entrega de otras aptas y suficientes para el desarrollo bumano; ninguna de ellas será enajenable, transmisible ni susceptible de gravámenes o embargos. Asegurar su participación en la gestión referida a sus recursos naturales y a los demás intereses que los afecten. Las provincias pueden ejercer concurrentemente estas atribuciones."

De este artículo me interesa abordar lo siguiente:

a) Reconocer la personeria jurídica de sus comunidades.

Ello significa que estas comunidades, cuya preexistencia se encuentra reconocida constitucionalmente, no requieren su inscripción en ningún registro. Es decir que la consecuente inscripción en algún registro es al solo efecto declarativo ${ }^{7}$. De esta manera, no es una obligación de las comunidades indígenas registrarse, por cuanto son personas y titulares de derechos, siendo deber del Estado reconocerles dicha personalidad jurídica, por manda constitucional.

En esa dirección, en el Caso Comunidad indígena Yakye Axa Vs. Paraguay, párrafo 82. la Corte Interamericana de Derechos Humanos consideró “...que el otorgamiento de personería jurídica sirve para hacer operativos los derechos ya existentes de las comunidades indígenas, que los vienen ejerciendo bistóricamente y no a partir de su nacimiento como personas jurídicas. Sus sistemas de organización política, social, económica, cultural y religiosa, y los derechos que ello apareja, como la designación de sus propios líderes y el derecho a reclamar sus tierras tradicionales, son reconocidos no a la persona jurídica que debe inscribirse para cumplir con un formalismo legal, sino a la comunidad en sí misma que la propia Constitución paraguaya reconoce como preexistente al Estado."

7 Es declarativa porque las comunidades tienen personería jurídica reconocida constitucionalmente, si fuera constitutiva, únicamente con la registración obtendría personería jurídica, no antes, (como lo establece la Ley $\mathrm{N}^{0}$ 23.302). 
b) Posesión y propiedad comunitaria de las tierras que tradicionalmente ocupan.

Antes de la llegada de los españoles a nuestro territorio, estos se encontraban habitados por los Pueblos Originarios. Con la colonización y luego con la independencia, a estos pueblos no se los reconoció y se les quitaron derechos, pero principalmente le fue negado su vínculo comunitario con las tierras.

Siguiendo la jurisprudencia relacionada con los reclamos de comunidades indígenas ${ }^{8}$, no hay que perder de vista que la posesión tradicional de los indígenas sobre sus tierras tiene los efectos equivalentes al título de pleno dominio que otorga el Estado. No obstante, es importante y necesario para las comunidades indígenas la obtención del título que refleje esa situación, que dicho título sea debidamente inscripto en los registros correspondientes a los efectos de dar la publicidad y oponibilidad frente a terceros de las situaciones jurídicas que detentan.

El Convenio $\mathrm{N}^{\circ} 169$ de la Organización Internacional del Trabajo en su artículo 141 ya expresaba: "Deberá reconocerse a los pueblos interesados el derecho de propiedad y de posesión sobre las tierras que tradicionalmente ocupan."

Es nuestra Carta Magna la que establece que esta propiedad especial, tiene una particularidad, que es la estrecha vinculación entre el pueblo indígena y el hábitat en el cual viven. Asimismo es dable destacar que esa relación pueblo-hábitat, se encuentra atravesada por connotaciones espirituales y religiosas (extrapatrimoniales), que les otorga su identidad, pues el eje central no es el individuo, sino el grupo o comunidad y su vinculación con la tierra, que les permite en esa conjunción preservar su cultura, lenguaje, valores, estilo de vida, organización, y el derecho. Estas particularidades, diferencian en gran medida a la propiedad comunitaria de la propiedad clásica (aquella perteneciente

8 Comunidad Mayagna awas Tingni vs. Nicaragua, Parr.151 y Comunidad Indígena Sawhoyamaxa vs Paraguay, Parr.128. 
a los derechos reales) por basarse esta última, principalmente en una mera relación de poder entre el sujeto y la cosa. ${ }^{9}$

Es por ello que sería muy difícil y engorroso intentar incorporar a la propiedad comunitaria dentro de las previsiones establecidas en el Código Civil y Comercial, por las enormes e insalvables diferencias que existen entre los derechos reales y esta propiedad especial (cuya regulación debería ser mediante una ley especial) ${ }^{10}$.

Existe una gran discusión doctrinaria respecto a esta cuestión, ya que en el Proyecto de Código Civil y Comercial de 2012 la propiedad comunitaria estaba prevista en la enumeración de los derechos reales, como uno más. Asimismo el Título V (conformado por los artículos 2028 a 2036) contenía el concepto, modos de constitución, caracteres, facultades y prohibiciones del titular y una consulta a las comunidades indígenas por cuestiones atinentes al aprovechamiento de los recursos naturales por parte del Estado o de particulares. El mayor inconveniente en la regulación dentro del código de fondo de la propiedad comunitaria, estaba dado por el artículo 2036 que proyectaba aplicarle subsidiariamente las disposiciones referidas al dominio a esta propiedad especial, en todo lo que no sea incompatible.

Para María V. González de Prada, en Derecho de las comunidades indigenas 11 "...la propiedad comunitaria de estos pueblos trasciende el concepto de derecho real que nosotros tenemos,

9 En las XXII Jornadas Nacionales de Derecho Civil realizadas en Córdoba en 2009, se declaró que "La propiedad comunitaria indígena es una propiedad especial de fuente constitucional (art. 75 inc $17 \mathrm{CN}$ ) cuya naturaleza real integra una compleja relación multidimensional de pertenencia de esos pueblos con su entorno físico, social y cultural, En estas Jornadas se recomendó la conveniente incorporación de la propiedad comunitaria en el Código Civil, votación por mayoría con oposición de la Dra. Vázquez".

10 Existen otras posturas que avalan la incorporación de los derechos indígenas en el Código Civil y Comercial, a los fines de ejercer supremacía sobre las legislaciones provinciales; ello no desjerarquizaría los derechos de raigambre constitucional, sino que afirman que los ubica en un plano de operatividad y obligatorio para las interpretaciones jurisprudenciales y las políticas públicas provinciales.

11 Publicado en LL 16/10/2013 -E,1296, cita online:AR/DOC/3884/2013 
porque no solo se refiere a la apropiación de las cosas, sino también a un modo de vida, de ser, de quebacer y de relacionarse con el otro."

Finalmente esa discusión ha quedado atrás, ya que con la sanción del Código Civil y Comercial el único artículo que se refiere a la propiedad comunitaria es el artículo 18 que establece: "Las comunidades indígenas reconocidas tienen derecho a la posesión y propiedad comunitaria de las tierras que tradicionalmente ocupan y de aquellas otras aptas y suficientes para el desarrollo bumano según lo establezca la ley, de conformidad con lo dispuesto por el artículo 75 inciso 17 de la Constitución Nacional." La crítica que corresponde realizar a este artículo, es la dificultad de establecer cuál sería el alcance que tiene el vocablo "reconocida", ya que denotaría la obligatoriedad de registrarse a los efectos de obtener ese reconocimiento, debiendo remitirme a lo expresado en el Punto II, parágrafo a), reafirmando lo dicho respecto a que no es una obligación de las comunidades indígenas registrarse por cuanto la misma constitución Nacional les reconoce personalidad jurídica. Cuadra mencionar que la comunidad indígena entendida como unidad sociopolítica, es un ente con personalidad jurídica propia susceptible de adquirir derechos y contraer obligaciones. El estado "reconoce" su personería jurídica, respetando sus mecanismos de representación y toma de decisiones, muy diferentes a los de la democracia representativa. ${ }^{12}$

En cuanto a los modos de adquisición de la propiedad comunitaria indígena, las XXIV Jornadas Nacionales de Derecho Civil decidieron que pueden ser de dos formas: a) Por reconocimiento del Estado Nacional, Provincial y/o Municipal de las tierras que tradicionalmente ocupan. ${ }^{13}$ b) Por actos entre

\footnotetext{
12 Kiper Claudio. Propiedad Indígena Derechos Reales. Novedades en el Código Civil y Comercial de la Nación (Ley 26.994)Rubinzal Culzoni Editores. Capítulo II por Liliana Abreut de Bergher. Pag 95 y ss.

13 Es responsabilidad del Estado la reparación de los derechos de terceros interesados de buena fe que pudieran resultar afectados
} 
vivos, actos de disposición de última voluntad y prescripción adquisitiva de otras tierras aptas para su desarrollo ${ }^{14}$

c) Regular la entrega de otras aptas y suficientes para el desarrollo bumano.

El artículo 14 de la Convenció $\mathrm{N}^{\circ} 169$ de la OIT sigue expresando: “...Además, en los casos apropiados, deberán tomarse medidas para salvaguardar el derecho los pueblos interesados a utilizar tierras que no estén exclusivamente ocupadas por ellos, pero a las que hayan tenido tradicionalmente acceso para sus actividades tradicionales y de subsistencia. A este respecto, deberá prestarse particular atención a la situación de los pueblos nómadas y de los agricultores itinerantes." "...Los gobiernos deberán tomar las medidas que sean necesarias para determinar las tierras que los pueblos interesados ocupan tradicionalmente y garantizar la protección efectiva de sus derechos de propiedad y posesión."

Es interesante transcribir asimismo el artículo 16 de la Mencionada Convención que contempla la posibilidad de otorgar tierras sustitutas por traslado. El artículo dispone: “...los interesados no deberán ser trasladados de las tierras que ocupan... Cuando excepcionalmente el traslado y la reubicación de esos pueblos se consideren necesarios, sólo deberán efectuarse con su consentimiento, dado libremente y con pleno conocimiento de causa. Cuando no pueda obtenerse su consentimiento, el traslado y la reubicación sólo deberá tener lugar al término de procedimientos adecuados establecidos por la legislación nacional, incluidas encuestas públicas, cuando haya lugar, en que los pueblos interesados tengan la posibilidad de estar efectivamente representados."

14 Conforme Punto 6 de las Conclusiones de la XXIV Jornadas Nacionales de Derecho Civil, 2da.parte, por mayoría, con la oposición de las Dras. Zamudio, González de Prada, Vázquez y Pujol. 
d) Ninguna de ellas será enajenable, transmisible ni susceptible de gravámenes o embargos.

Estas son algunas de las particularidades que tiene la propiedad comunitaria que la diferencia de los derechos reales establecidos en el Código Civil y Comercial. El ser intransmisible y pertenecer únicamente a la comunidad indígena, no forma parte del acervo sucesorio de los individuos que la componen. ${ }^{15}$

Agrego en concordancia con algunas de las conclusiones arribadas en las XXIV Jornadas Nacionales de Derecho Civil, realizadas en Buenos Aires en el año 2013, que no es una propiedad individual, sino comunitaria, ${ }^{16}$ es perpetua ${ }^{17}$, es exclusiva, ${ }^{18}$ es imprescriptible e indivisible ${ }^{19}$. La Propiedad comunitaria subsiste mientras no se extinga la comunidad indígena.

\section{Legislación Nacional}

La Ley Nacional $N^{o} 23.302$ de Protección de las Comunidades Indígenas ${ }^{20}$, reconoce los derechos de los pueblos originarios, pero tuvo el desacierto de pretender que estos pueblos se adecuen de alguna manera a la normativa por ese entonces vigente, desconociendo su preexistencia a la nación y su vínculo originario con la tierra con la cual se identifican, perdiendo su principal objetivo con la reforma constitucional de 1994 y el reconocimiento realizado en el inciso 17 artículo 75 de la Constitución Nacional.

\footnotetext{
15 No se aplican las disposiciones del Derecho Sucesorio. En caso de que la comunidad desaparezca (por muerte o desaparición de todos sus integrantes, se prevé que el bien vuelva al Estado.

16 No hay cotitulares o condóminos, la titularidad no recae sobre los integrantes de la comunidad.

17 No se extingue por el no uso y no está subordinada a plazo o condición.

18 Deriva de tener un único titular: la comunidad indígena.

19 Ambas particularidades indican que estas tierras no pueden ser adquiridas por usucapión por un tercero.

20 Sancionada en 1985 (modificada por Ley № 25.799).
} 
Entre las particularidades de esta Ley, menciono las siguientes: creó la Comisión Nacional de Asuntos Indígenas; dispuso la adjudicación en propiedad a las comunidades indígenas existentes en el país, debidamente inscriptas, de tierras aptas y suficientes para la explotación agropecuaria, forestal, minera, industrial o artesanal, según las modalidades propias de cada comunidad, esa adjudicación de tierras será a título gratuito; deben destinarse a la explotación agropecuaria, forestal, minera, industrial o artesanal en cualquiera de sus especialidades, sin perjuicio de otras actividades simultáneas; las tierras son inembargables e inejecutables; en los títulos respectivos se hará constar la prohibición de su enajenación durante un plazo de veinte años a contar de la fecha de su otorgamiento; en caso de extinción de la comunidad o cancelación de su inscripción, las tierras adjudicadas a ellas pasarán a la Nación o a la Provincia o al Municipio según su caso. El miembro de una comunidad adjudicataria de tierras que las abandone no podrá reclamar ningún derecho sobre la propiedad; los que le correspondieren quedarán en beneficio de la misma comunidad a que pertenecía. El Instituto Nacional de Asuntos gestionará la habilitación de planes especiales para la construcción de viviendas, preferentemente con materiales, técnicas utilizadas por cada comunidad, mano de obra propia, del Banco Nación, el FONAVI y de cualquier otro plan habitacional de fomento.

La Ley $26.160^{21}$ declaró la emergencia en materia de posesión y propiedad de las tierras que tradicionalmente ocupan las comunidades indígenas originarias del país, cuya personería jurídica haya sido inscripta en el Registro Nacional de Comunidades Indígenas u organismo provincial competente o aquellas preexistentes, por el término de 4 (cuatro) años. Durante los 3 (tres) primeros años, el Instituto Nacional de Asuntos Indígenas deberá realizar el relevamiento técnico -jurídico- catastral de la

21 Los plazos establecidos en esta ley, fueron prorrogados por Ley N ${ }^{0} 26554$ (B.0. 11/12/2009), por Ley N 26894 (B.0. 21/10/2013)-hasta el 23 de noviembre de 2017-Ley N 27400 (B.0. 23/11/2017)-hasta el 23 de noviembre de 2021. 
situación dominial de las tierras ocupadas por las comunidades indígenas y promoverá las acciones que fueren menester con el Consejo de Participación Indígena, los Institutos Aborígenes Provinciales, Universidades Nacionales, Entidades Nacionales, Provinciales y Municipales, Organizaciones Indígenas y Organizaciones no Gubernamentales. Esta ley esta imbuida por políticas públicas destinadas a realizar relevamientos de la situación dominial de las tierras ocupadas por comunidades indígenas, esto es una herramienta fundamental que debería tener el carácter de permanente ya que es indispensable para la organización territorial y para respetar derechos de los pueblos originarios, pero no resuelve ni aporta herramientas relacionadas con la instrumentación de los títulos de esas tierras.

\section{Regulación en provincia de Buenos Aires}

La Constitución de la Provincia de Buenos Aires en su artículo $36^{\circ}$ inciso 9 establece: "Que la Provincia promoverá la eliminación de los obstáculos económicos, sociales o de cualquier otra naturaleza, que afecten o impidan el ejercicio de los derechos y garantías constitucionales... 9- De los Indígenas. La Provincia reivindica la existencia de los pueblos indígenas en su territorio, garantizando el respeto a sus identidades étnicas, el desarrollo de sus culturas y la posesión familiar y comunitaria de las tierras que legítimamente ocupan.

La Provincia de Buenos Aires, adhiere al contenido de la Ley $\mathrm{N}^{\mathrm{o}} 23.202$ mediante la Ley Provincial $\mathrm{N}^{\mathrm{o}}$ 11.331, reglamentada por el Decreto número 3631/07. Este decreto instaura en su artículo 4 “...Inciso 3: garantizar el resguardo de las identidades culturales de los pueblos indígenas, promoviendo la conservación y transmisión de sus pautas culturales y cosmovisiones; fortaleciendo las capacidades de las comunidades indígenas; y afianzando los vínculos inter e intra comunitarios.- Inciso 4Contribuir a la construcción de una sociedad intercultural, en la que se respeten todas las identidades y se valore la diversidad a través de la reivindicación histórica de los pueblos indígenas, 
la difusión de sus expresiones culturales, la promoción de sus derechos y la erradicación de conductas discriminatorias..."

\section{Adjudicación a título gratuito de tierras a favor de la "Comunidad Nam Qom"}

En diciembre del año 2014, la Comunidad Nam-Qom, perteneciente al Pueblo Toba ${ }^{22}$, logró suscribir el título formal de tierras situadas en la Provincia de Buenos Aires. Esta comunidad es reconocida por el Instituto Nacional de Asuntos Indígenas (INAI) y se encuentra inscripta en el Registro Nacional de Comunidad Indígenas (RE.NA.CI), con personería jurídica.- Del Reglamento de la Comunidad Nam Qom surge que su autoridad máxima es el cacique, cuyo mandato tiene un plazo de veinte años consecutivos e ininterrumpidos, con facultades para ejercer la representación de la comunidad en todos los ámbitos y gestionar proyectos que fortalezcan la comunidad en su conjunto. La designación y elección del Cacique surge de las constancias de su acta de asamblea general ordinaria y mediante las constancias del Acta del Consejo de la Comunidad Nam Qom, resolvieron por unanimidad la aceptación de la adjudicación de propiedad comunitaria con título colectivo de las tierras mencionadas.

La escritura de adjudicación de las tierras, fue el broche final, de un exhaustivo camino que comenzó a transitar mucho tiempo antes, la Comunidad Nam Qom, en principio migrando desde sus tierras originarias hasta el partido de La Plata, en la búsqueda de mejorar su calidad de vida. Golpearon infinidad de puertas en innumerable cantidad de organismos e instituciones, se esforzaron por integrarse con la población e intentaron preservar su cultura, recabaron información, se formaron, aprendieron y tramitaron infinidad de trámites administrativos, todo ello una y cien veces, con la fuerza y el temple necesarios

22 Comunidad originaria de Chaco y parte de Formosa, llegó hace aproximadamente 25 años atrás a la ciudad de La Plata, en busca de mejores condiciones de vida. 
para lograr sus metas. En ese escenario, se animaron a elevar sus voces y lograron que sus reclamos sean escuchados, sintiéndose cada vez más cercanos a que sus sueños sean traducidos en una floreciente realidad. El vínculo de la Comunidad Nam Qom con las tierras en donde viven, trabajan, se educan y se relacionan, benefició a 45 familias integrantes. El acceso a las tierras y sus títulos, les permitió preservar su identidad cultural, afianzar sus costumbres, su lengua, su idiosincrasia, alcanzando una mejor calidad de vida y mayor arraigo, con el consecuente incremento de la seguridad jurídica, materializando cabalmente el derecho a la propiedad comunitaria.

En función de ello, se pusieron en marcha políticas públicas y a través de organismos tanto nacionales como provinciales, asumieron el compromiso de gestionar la entrega de tierras "aptas y suficientes que contribuyan al desarrollo con identidad, brindado asistencia técnica y asegurando la plena participación de las comunidades durante el proceso de regularización dominial, así como las respectivas escrituras, y posterior inscripción registral para la oponibilidad frente a terceros.

El progreso de estas gestiones fue realizándose en las siguientes etapas:

a) Por un Convenio celebrado el 19 de octubre de 1999 entre la Comunidad Nam Qom y el Instituto de la Vivienda de la Provincia de Buenos Aires, este último le otorga la posesión de inmuebles sitos en el partido de La Plata.

b) Con posterioridad, es el Instituto Nacional de Asuntos Indígenas quien mediante Resolución de su Presidente $\mathrm{N}^{\mathrm{o}} 103$ del año 2011, realizó el Relevamiento Técnico, Jurídico y Catastral dispuesto por el Artículo $3^{\circ}$ de la Ley Nacional $\mathrm{N}^{\mathrm{o}} 26.160$, Decreto PEN No 1122/07 y la Resolución INAI N $587 / 07$ en la comunidad Nam Qom, con asiento en la Provincia de Buenos Aires, reconociéndole asimismo a esa comunidad la ocupación actual, tradicional y pública de la tierra.

c) El Instituto de la Vivienda de la Provincia de Buenos Aires, por Resolución No 1720 del 29 de mayo de 2014, adjudicó 
a título gratuito a la Comunidad Nam Qom, la propiedad comunitaria de los inmuebles identificados ubicados en el partido de La Plata, en los términos de los artículos 10 y 12 de la Ley Nacional $\mathrm{N}^{\circ} 23.302$ y Ley Provincial $\mathrm{N}^{\circ} 11.331$, con los alcances preceptuados por el art. 75 inciso 17 de la Constitución Nacional, dándole intervención a la Escribanía General de Gobierno a fin de extender la pertinente escritura traslativa de dominio.

d) La Escribanía General de Gobierno de la provincia de Buenos Aires autorizó la escritura de propiedad comunitaria a favor de la Comunidad Nam Qom, como adjudicataria a título gratuito y colectivo de tierras ubicadas en la ciudad de la Plata.

e) Este proceso, continuó con la inscripción de los títulos en la Dirección Provincial del Registro de la Propiedad de la Provincia de Buenos Aires, que en cumplimiento de normativa registral, produjo la oponibilidad frente a terceros. Las características particulares de la propiedad comunitaria, hicieron necesario plasmar en los folios reales de los inmuebles, específicamente en la columna destinada a las restricciones al dominio, nota con algunas previsiones importantes plasmadas en la Ley Nacional $\mathrm{N}^{\circ}$ 23.203. Entre ellas se dejó constancia de que estas tierras son inembargables e inejecutables; que en sus títulos respectivos deberá constar la prohibición de su enajenación durante un plazo de veinte años a contar de la fecha de su otorgamiento; que los adjudicatarios están obligados a radicarse en las tierras asignadas y trabajarlas personalmente; no vender, arrendar o transferir bajo ningún concepto o forma sus derechos sobre la unidad adjudicada, ni subdividir o anexar las parcelas sin autorización de la autoridad de aplicación. La sanción prevista en la Ley para los actos jurídicos realizados en contravención a esta norma, serán reputados nulos a todos sus efectos. Por último, se dejó nota de que en caso de extinción de la comunidad o cancelación de su inscripción, las tierras adjudicadas a ellas pasarán a la Nación o a la Provincia o al Municipio, según su caso. 


\section{Conclusión}

Del análisis efectuado en el presente trabajo, se desprende la falta de políticas públicas y de mecanismos que permitan concretar el acceso a los títulos de la propiedad comunitaria, cuya fuente es constitucional, y ello se ve reflejado en la judicialización de los conflictos territoriales.

Frente a estos vacíos, urge la necesidad de dictar una ley que contemple y regule la propiedad comunitaria de los Pueblos Originarios, y establezca políticas claras y transparentes tendientes a la obtención de las respectivas escrituras públicas de las tierras a favor de las comunidades indígenas, con su consecuente inscripción en los Registros de la Propiedad Inmuebles, para su oponibilidad frente a los terceros.

Como última reflexión quiero compartir el legado de las XXIV Jornadas Nacionales de Derecho Civil en la Comisión 9, fueron a un fiel reflejo del respeto a la biodiversidad y el multiculturalismo, aportando claridad y abordando multidisciplinariamente la temática. Reconocieron la existencia de regímenes jurídicos de diferente origen -el derecho indígena y el derecho romano trasvasado a nuestro derecho patrio- que mediante un análisis intercultural permite arribar a soluciones valiosas que contemplen las particularidades de ambos, de modo que la cohabitación de culturas sea el norte que oriente las decisiones.

\section{Bibliografía}

Abreut de Begher, Liliana El derecho real de propiedad comunitaria indígena Publicado en: LA LEY 11/10/2013, 11/10/2013, 1 - LA LEY 2013-E, 1292 - LA LEY 11/10/2013, 1 Cita Online: AR/DOC/3785/2013 La propiedad comunitaria indígena. Comentario del Anteproyecto de Código Publicado en: LA LEY 07/06/2012, 07/06/2012, 1 - LA LEY 2012-C, 1238 Cita Online: $\mathrm{AR} / \mathrm{DOC} / 2503 / 2012$

Alterini, Jorge Horacio Código Civil y Comercial comentado. Tratado exegético - 2a ed. - Ciudad Autónoma de Buenos Aires: La Ley, 2016. v. 1, 1424 p. ; ISBN 978-987-03-3138-4 
Bidart Campos, Germán J La descentralización política de las comunidades indígenas: ¿qué nos aporta la ciencia política para el Derecho Constitucional? Publicado en: LA LEY 2001-C, 1417 Cita Online: AR/DOC/8574/2001

González de Prada, María Victoria. Derecho de las Comunidades Indigenas Publicado en: LA LEY 16/10/2013, 16/10/2013, 1 - LA LEY 2013-E, 1296 - LA /10/2013, 1 Cita Online: AR/DOC/ $3884 / 2013$

Hualpa, Eduardo R Las Comunidades Indígenas y los Derechos de Incidencia Colectiva Las Comunidades Indígenas y los Derechos de Incidencia Colectiva

Kozak, Verónica - Valdés, Gustavo Desintegración étnica, propiedad comunitaria indígena y prescripción adquisitiva Publicado en: LLBA2016 (diciembre), 3 Cita Online: AR/DOC/3529/2016

Smayevsky Miriam Derechos reales. - 1a ed. - Ciudad Autónoma de Buenos Aires: La Ley, 2015. 944 p. ; ISBN 978-987-03-2841-4 CDD 346.043

Vazquez Gabriela A. Propiedad Comunitaria indígena en el Proyecto Publicado en: LA LEY 12/07/2012, 12/07/2012, 1 - LA LEY 2012-D, 948 Cita Online: AR/DOC/3338/2012 